\title{
ПОКАЗАТЕЛИ КАЧЕСТВА ЖИЗНИ СТАРШЕГО ПОКОЛЕНИЯ: СОДЕРЖАНИЕ И ПУТИ ВЛИЯНИЯ НА НИХ СРЕДСТВАМИ ОРГАНИЗАЦИЙ
}

\author{
(C) 2020 Басова Мария Михайловна \\ кандидат экономических наук, доцент Департамента учета, анализа и аудита \\ Финансовый университет при Правительстве Российской Федерации, Россия, Москва \\ E-mail:MMBasova@fa.ru
}

Статья посвящена одной из актуальных проблем современного российского общества. В ней рассмотрены объективные показатели качества жизни, их отражение в жизни старшего поколения. На основе анализа нефинансовой отчетности организаций в рамках их устойчивого развития показано влияние социальных программ на улучшение качества жизни пенсионеров.

Ключевые слова: качество жизни; социальное самочувствие; аспекты устойчивого развития организаций; социальные программы; нефинансовая отчетность; пенсионное обеспечение; негосударственные пенсионные программы; поддержка пенсионеров.

Одна из глобальных проблем современной цивилизации - устойчивый рост социальнодемографической группы пожилых людей. Численность лиц этого возраста увеличивается как абсолютно, так и относительно, что ведет к заметным изменениям демографической структуры общества.

Пожилые люди - это часть населения страны, как правило, не принимающие участия в трудовой деятельности в связи с достижением установленного законом пенсионного возраста.

Общей тенденцией XXI века стали глобальные беспрецедентные перемены, связанные со старением населения и увеличением продолжительности жизни по всему миру и «К 2050 году пожилые люди (определяемые как в возрасте 60 лет или старше) будут составлять более одной пятой от общей численности населения мира (22\%), при этом их численность составит 2,03 млрд. чел. против нынешних 809 млн. (11\%)» [3].

В субъективном плане для пожилого человека выход на пенсию сопровождается изменением образа и стиля жизни, материального положения, возникновением необходимости адаптироваться к культурным и бытовым переменам. «Привыкание» к старости протекает не безболезненно как для самого человека, так и для его окружения. Осложняется этот процесс еще и происходящими бурными социальноэкономическими и духовными катаклизмами, влияющими на качество жизни старшего поколения.

Качество жизни - понятие, отражающее характеристику всех сторон общественной прак- тики личности, уровень удовлетворения её материальных, духовных и социальных потребностей, меру интеллектуального, культурного и физического развития, а также степень обеспечения безопасности жизни. Эта категория включает физическое, психологическое, эмоциональное и социальное здоровье человека, основанное на его оценках своего места в социуме. Обычно она демонстрируется показателями здравоохранения, образования, демографии, экономических условий, состоянием экологии, быта и возможностью реализации правовых норм.

Качество жизни характеризует структуру потребностей человека и возможности их удовлетворения. Общепринятыми показателями качества жизни населения являются: уровень доходов, качество питания и одежды; комфорт жилища; качество медицинских и социальных услуг; качество образования, культуры и сферы обслуживания; состояние окружающей среды; структура досуга; демографические тенденции; обеспечение безопасности жизнедеятельности.

Рассмотрение вышеназванных характеристик применительно к пожилому населению позволяет определить пиковые показатели, в которых люди старшего возраста наиболее уязвимы и требуют специального внимания и защиты.

Материальное обеспечение оценивается уровнем доходов, показателями покупательских возможностей, наличием предметов длительного пользования. Выход на пенсию, как правило, связан со снижением уровня материального положения, зависимостью от инфляции, ростом затрат на лекарства и медицинское обслуживание. 
Ухудшается качество питания, испытываются затруднения в приобретении одежды и обуви, снижаются расходы на развлекательные мероприятия. Все это оказывает негативное влияние на здоровье пожилых людей, рождает неуверенность в завтрашнем дне.

Состояние здоровья пожилых людей традиционно находится на одном из первых мест оценки качества жизни. «Снижение качества жизнедеятельности порождается уровнем заболеваемости у пожилых людей в 2 раза, а в старческом возрасте - в 6 раз выше, чем у молодых. Это хронические заболевания (суставные, сердечнососудистые и т.д.), понижение слуха, зрения, ортопедические проблемы. В среднем на одного пожилого больного в России приходится от 2 до 4 заболеваний, а стоимость лечения пожилых в $1,5-1,7$ раза больше, чем молодого контингента» [4]. Явно недостаточно развита и система занятия физкультурой для пожилых граждан.

Социальное самочувствие отражает субъективную оценку качества жизни. Потеря супруга, отделение взрослых детей, смена круга общения, часто - одиночество не могут способствовать ощущению оптимизма и веры в светлое будущее. Пожилые люди часто ощущают дискомфорт от профессиональной невостребованности и социальной изолированности. Для многих из них пока еще остаются недоступными современные информационные технологии

Решение названных и других проблем пожилых людей осуществляется как путем реализации государственной политики на федеральном и региональном уровнях, так и акциями общественных организаций и коммерческих структур. Успех в этой работе должен обеспечить системный подход при реализации государственных программ Российской Федерации «Социальная поддержка граждан» [6] и «Содействие занятости населения» [7], а также соответствующих программ субъектов России.

Новые аспекты работы с гражданами пожилого возраста были привнесены недавними изменениями в законодательстве. «С 1 января 2019 года вступил в действие закон о повышении пенсионного возраста, который предполагает, что пенсионный возраст будет повышаться с 2019 года ежегодно на 1 год, кроме первых двух лет, когда будут действовать льготные условия по выходу на пенсию - на 6 месяцев раньше срока, установленного новым законом. Окончательные значения для мужчин и женщин (соот- ветственно 65 и 60 лет) будут установлены с 2023 года» [8]. Для лиц пред пенсионного возраста закон изменил жизненные планы и скорректировал установки на ближайшие годы.

Забота о повышении качества жизни граждан старшего поколения имеет и политический аспект. Пенсионеры составляют значительную и постоянно растущую часть электората. Их позиция на выборах органов власти всех уровней в силу традиционной активности к выполнению конституционного права выражает отношение к властям и во многом определяет исход голосования.

В этой связи, потребуется внесение новаций и в работу организаций, занимающихся обеспечением комплексной заботы о лицах старшего поколения. В настоящее время различные аспекты устойчивого развития организаций выражаются в разработке и реализации разнообразных социальных программ, в том числе и направленных на повышение качества жизни бывших работников, которые находят отражение в нефинансовой отчетности.

Анализ нефинансовой отчетности ряда организаций [5] позволил сгруппировать социальные программы направленные на повышение качества жизни бывших работников организаций (рисунок 1).

1. В качестве примеров программ пенсионного обеспечения и социальной поддержки пенсионеров и ветеранов, направленные на реализацию материального и нематериального обеспечения лиц старшего возраста можно привести следующие проекты:

- «Пенсионное обеспечение» (ПАО «ЛУКОЙЛ», ПАО «СЕВЕРСТАЛЬ»);

- Негосударственные пенсионные программы для пенсионеров - членов Совета ветеранов ВЭБ (ВНЕШЭКОНОМБАНК);

- Программы социальной поддержки пенсионеров - бывших работников (КОМПАНИЯ «МЕТАЛЛОИНВЕСТ»);

- Программы по поддержке ветеранов (АО «КАМЕНСКВОЛОКНО»);

- Повышение уровня жизни работников, членов их семей и неработающих пенсионеров (ОАО «РЖД»);

- Социальные, волонтерские и благотворительные проекты АФК «Система» помощи людям пожилого возраста и с ограниченными возможностями здоровья (ОВ3), в т.ч. программа «Забота о ветеранах» реализуемая на базе согла- 


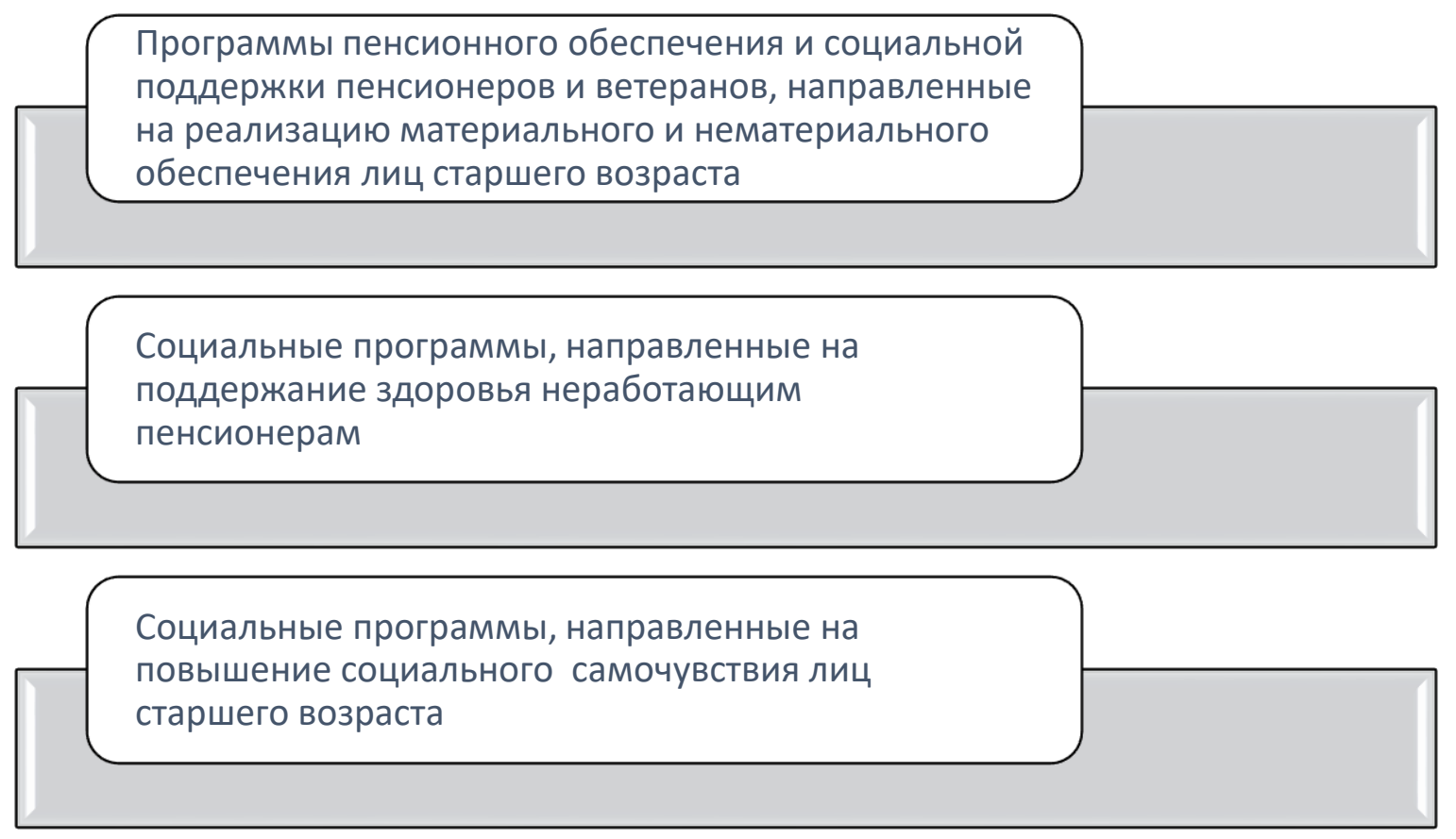

Puc. 1.

шения с Правительством Москвы и Московским городским советом ветеранов.

- Поддержка трудовых династий и других традиций коллектива (ПАО «ММК»),

- Поддержка пожилых людей (ВНЕШЭКОНОМБАНК).

Программа «Активное долголетие» (ПАО «ММК»), направленна на сохранение трудоспособности работников старших возрастных групп. В рамках этого проекта за последние 5 лет предоставляется помощь в среднем 5 тыс. чел. в год. В частности, за январь-июнь 2018 года 157,4 миллиона рублей было направлено на реализацию программы «Забота» магнитогорского благотворительного фонда «Металлург». Крупнейшим благотворителем последнего является ПАО «ММК». Входящие в «Заботу» подпрограммы направлены на повышение уровня и качества жизни людей старшего поколения. Так, в рамках «Старшего поколения» более 14000 неработающих пенсионеров комбината и других предприятий и учреждений ежемесячно получают материальную помощь, а 3000 пенсионеровбюджетников - ежеквартально. 120 человек бесплатно обедают в столовой «Ветеран».

2. Социальные программы, направленные на поддержание здоровья неработающим пенсионерам. Приведем примеры.

Программа «Сохрани свое здоровье» «ПАО «MMК» подразумевает помощь с оплатой ле- чения, медикаментов, средств реабилитации, оказанием стоматологической и высокотехнологичной медпомощи, «Активное долголетие» дает возможность поправить пенсионерам здоровье в учреждениях здравоохранения.

3. Социальные программы, направленные на повышение социального самочувствия лиц старшего возраста.

Приведем конкретные примеры. Совместно с советами ветеранов ПАО «ММК» и других организаций-благотворителей насыщается досуг пожилых людей. Пенсионеры, ограниченные в движении, получают подарки на дому, направляется материальная помощь, подарки и продуктовые наборы. В 2018 году 695 человек приняли участие в литературно-музыкальных гостиных и творческих встречах, 136 бесплатно посмотрели спектакли драмтеатра «Женитьба» и «Ханума», еще 120 человек получили билеты на спектакль «Вива, опера!» в театр оперы и балета.

Федеральный социально-просветительский проект «Сети все возрасты покорны» ПАО «МТС» направлен на обучение пожилых людей пользованию мобильной связью. Проект ПАО «МТС» «Социальный HR», направлен на поддержку и проведение мероприятий, которые направлены на привлечение на работу и дальнейшую адаптацию сотрудников зрелого возраста.

Многие годы ПАО «ЛУКОЙЛ» в Перми реа- 
лизует образовательную программу для пенсионеров и ветеранов, цель которой - вовлекать пожилых людей в активную социальную жизнь. Для них проводятся лекции по социальноправовым и медицинским вопросам, встречи с людьми искусства и музыкальными коллективами.

С 2005 года в Пуровском районе ЯНАО создан Фонд социальной защиты «НОВАТЭК-Ветеран» (Фонд). Главная задача Фонда - оказание помощи социального характера пенсионерам, которые на протяжении продолжительного времени работали в нефтегазовой отрасли в условиях Крайнего Севера. В 2018 году были организованы различные мероприятия, концерты и творческие вечера для пенсионеров. Работники Фонда поздравили ветеранов Великой Отечественной войны и тружеников тыла с Днем Победы. В честь праздника ветераны получили денежные выплаты, цветы и подарки. В течение 2018 года для поддержки пенсионеров Фонд продолжил сотрудничество с организациями и предприятиями г. Тарко-Сале. Совместно с Центральной клубной системой Пуровского района в течение года было организовано посещение пенсионерами 17 культурно-массовых мероприятий. В рамках сотрудничества с муниципальным бюджетным учреждением физкультурноспортивной организацией «Спортивная школа олимпийского резерва «Авангард» пенсионерам была предоставлена возможность бесплатного посещения тренажерного кардиозала в спортивном комплексе. С муниципальным бюджетным учреждением «Комплексный центр социального обслуживания населения Пуровского района» была налажена работа патронажной службы для помощи пенсионерам. На конец 2018 года в Фонде зарегистрированы 844 пенсионера. В 2018 году ежеквартальная материальная помощь каждому пенсионеру составила 6240 рублей, что на 240 рублей больше, чем в 2017 году. Всего в 2018 году на финансирование Фонда Компания направила 31,5 млн. рублей.

Разрабатываемые организациями социальные программы не ограничиваются заботами только о своих бывших сотрудниках, но и в значительной степени содействуют повышению качества жизни пенсионеров в регионах присутствия.

Социальные программы повышения (улучшения) качества жизни старшего поколения 8 регионах присутствия (местных сообществ) в области развития образования, культуры, искусства и спорта представлены в нефинансовой отчетности следующих компаний: ПАО «СЕВЕРСТАЛЬ», ОК РУСАЛ, АО «СУЭК», Объединенная металлургическая компания (ОМК), АО «МХK «ЕВРОХИМ», ПАО «МТС», ПАО АФК «СИСТЕМА», ПАО «ЛУКОЙЛ», ПАО «НОВАТЭК», ПАО «ГАЗПРОМ НЕФТЬ», КОМПАНИЯ «МЕТАЛЛОИНВЕСТ» и др.

Так, например, ОК РУСАЛ заключила соглашения о социально-экономическом партнерстве с семью регионами присутствия, в рамках которых профинансировано жилищное строительство, создание и реконструкция объектов здравоохранения, образования, спортивнооздоровительного и дорожно-транспортного назначения. Объем инвестиций в 2016-2017 гг. составил 734,5 млн. руб. Разработана стратегия градостроительного развития моногорода Ачинска, политика социального развития нескольких городов.

АО «МХК «ЕВРОХИМ» разработало программу повышения качества жизни в малых городах («Качественная среда для жизни»), целью которой является повышение качества жизни людей (в том числе и пенсионеров) в небольших российских городах, где расположены предприятия ЕвроХима.

Волонтерское движения МТС ставит своей целью повышение качества жизни общества и решение острых социальных проблем в субъектах присутствия компании. Приоритетные направления: улучшение здоровья и содействие гармоничному развитию подрастающего поколения, поддержка и социализация представителей старшего поколения, поддержка инвалидов и ветеранов, забота об окружающей среде, сохранение и развитие культурного и исторического наследия регионов присутствия МТС.

Основные целевые аудитории и объекты волонтерской деятельности:

- дети до 18 лет, а также их ближайшие родственники и опекуны;

- ветераны и инвалиды Великой Отечественной войны, труда и отрасли «Связь»;

- благотворительные фонды и общественные организации, оказывающие поддержку: детству и юношеству; людям старшего возраста; ветеранам и инвалидам Великой Отечественной войны, труда и отрасли «Связь»; развитию полезного и безопасного контента в сети Интернет; занимаются охраной окружающей среды; зани- 
маются сохранением и развитием культурного и исторического наследия регионов присутствия Группы МТC.

В компании «Газпром нефть» принята программа социальных инвестиций «Родные города», одним из проектов которой является улучшение качества жизни людей с ограничениями здоровья.

Таким образом, в интересах повышения качества жизни пенсионеров большое число коммерческих организаций действуют на основе федерального и местного законодательства совместно с органами государственной власти и местного самоуправления. Их деятельность представляет собой адресную помощь конкретной целевой группе - гражданам старшего по- коления.

Такая поддержка пенсионеров - это дополнение мер, предпринимаемых государством для улучшения положения лиц «третьего возраста», увеличения продолжительности жизни, поддержания здоровья, сохранения интересов и потребностей, социальной адаптации в целом, купирования неизбежных возрастных проблем.

Кроме реализации общегуманитарных целей организации такими действиями способствуют своему устойчивому развитию, росту авторитета и благоприятному имиджу в общественном сознании, использованию опыта старших поколений, привлечению новых сотрудников гарантиями их будущего.

\section{Библиографический список}

1. Басова М.М. Основные проблемы корпоративной социальной ответственности бизнеса и пути их решения // Стратегии бизнеса. 2017. № 2 (34). С. 16-20.

2. Басова М.М. Построение рейтингов организаций на основе анализа социальных аспектов их устойчивого развития // Известия Юго-Западного государственного университета. Серия: Экономика. Социология. Менеджмент. 2016. № 1 (18). С. 126-135.

3. Галущинская Ю.О. К проблеме повышения качества жизни лиц пожилого возраста // Вестник Шадринского государственного педагогического института. 2015. № 2 (26). С. 94-100.

4. Медведев Н.В. Функциональная недостаточность и качество жизни лиц пожилого и старческого возраста с полиморбидностью: диссертация ... кандидата медицинских наук: 14.00.52 / Медведев Николай Вячеславович; [Место защиты: Российский научно-исследовательский институт геронтологии].-Москва, 2004.-116 с.: ил

5. Официальный сайт Российского союза промышленников и предпринимателей [Электронный ресурс] URL: http://www.rspp.ru (дата обращения: 10.10.2019).

6. Постановление Правительства Российской Федерации от 15 апреля 2014 г. № 296

7. Постановление Правительства Российской Федерации от 15 апреля 2014 г. № 298

8. Федеральный закон «О внесении изменений в отдельные законодательные акты Российской Федерации по вопросам назначения и выплаты пенсий» от 3 октября 2018 года 